Article

\title{
Fuzzy Logic Approach to Dissolved Gas Analysis for Power Transformer Failure Index and Fault Identification
}

\author{
Nitchamon Poonnoy ${ }^{1}$, Cattareeya Suwanasri ${ }^{1, *}$ and Thanapong Suwanasri ${ }^{2}$ \\ 1 Department of Electrical and Computer Engineering, Faculty of Engineering, King Mongkut's University of \\ Technology North Bangkok (KMUTNB), Bangkok 10800, Thailand; nitchamon.p@fte.kmutnb.ac.th \\ 2 Department of Electrical and Software Systems Engineering, The Sirindhorn International Thai-German \\ Graduate School of Engineering (TGGS), KMUTNB, Bangkok 10800, Thailand; \\ thanapong.s.epe@tggs-bangkok.org \\ * Correspondence: cattareeya.s@eng.kmutnb.ac.th; Tel.: +66-851-410-072
}

\section{check for}

updates

Citation: Poonnoy, N.; Suwanasri, C.; Suwanasri, T. Fuzzy Logic Approach to Dissolved Gas Analysis for Power Transformer Failure Index and Fault Identification. Energies 2021, 14, 36. https://dx.doi.org/10.3390/en14010036

Received: 12 November 2020 Accepted: 20 December 2020 Published: 23 December 2020

Publisher's Note: MDPI stays neutral with regard to jurisdictional claims in published maps and institutional affiliations.

Copyright: () 2020 by the authors. Licensee MDPI, Basel, Switzerland. This article is an open access article distributed under the terms and conditions of the Creative Commons Attribution (CC BY) license (https: / / creativecommons.org/ licenses/by/4.0/).
Abstract: This research focuses on problem identification due to faults in power transformers during operation by using dissolved gas analysis such as key gas, IEC ratio, Duval triangle techniques, and fuzzy logic approaches. Then, the condition of the power transformer is evaluated in terms of the percentage of failure index and internal fault determination. Fuzzy logic with the key gas approach was used to calculate the failure index and identify problems inside the power transformer. At the same time, the IEC three-gas ratio and Duval triangle are subsequently applied to confirm the problems in different failure types covering all possibilities inside the power transformer. After that, the fuzzy logic system was applied and validated with DGA results of 244 transformers as reference cases with satisfactory accuracy. Two transformers were evaluated and practically confirmed by the investigation results of an un-tanked power transformer. Finally, the DGA results of a total of 224 transformers were further evaluated by the fuzzy logic system. This fuzzy logic is a smart, accurate tool for automatically identifying faults occurring within transformers. Finally, the recommendation of maintenance strategy and time interval is proposed for effective planning to minimize the catastrophic damage, which could occur with the power transformer and its network.

Keywords: dissolved gas analysis; Duval triangle; key gas method; IEC 60599; power transformer; total dissolved combustible gases

\section{Introduction}

The power transformer is a key component in power transmission and distribution systems. During operation, it might be deteriorated by both normal and abnormal conditions, including overloading, aging, and degradation of paper-oil insulation, internal arcing and partial discharge (PD), short circuit, etc. Survey results [1] show damages within power transformers including on-load tap changer (OLTC), winding and iron core, bushing, tank, and other related damages. Therefore, to prevent failure and to maintain the power transformer in the satisfactorily working condition, several traditional and nontraditional diagnostic methods have been performed to assess the condition [2,3]. The traditional diagnostic methods are dissolved gas analysis, oil quality, power factor testing, winding resistance measurement, turn ratio, and thermography, while the nontraditional diagnostic methods are partial discharge measurement, dielectric spectroscopy, frequency response analysis, tap changer monitoring, and internal temperature measurement. After obtaining the test results from various diagnostic methods mentioned above, the data has been further evaluated to assess the condition of the power transformer, mainly based on health index value by applying a scoring and weighting algorithm [4]. However, this traditional health index determination has some drawbacks because it requires many test results from transformer electrical tests and oil diagnostics to complete the evaluation 
process, as well as the influence of weight determination on the uncertainty of the obtained health index result [4].

Several defects can occur with a power transformer and lead to a shorter transformer life, malfunction, unplanned outage, etc., which directly affect the increase in the amount of specific gases dissolved in insulating oil within the transformer tank, such as methane $\left(\mathrm{CH}_{4}\right)$, ethane $\left(\mathrm{C}_{2} \mathrm{H}_{6}\right)$, acetylene $\left(\mathrm{C}_{2} \mathrm{H}_{2}\right)$, and ethylene $\left(\mathrm{C}_{2} \mathrm{H}_{4}\right)$, as well as other gases such as carbon monoxide $(\mathrm{CO})$, carbon dioxide $\left(\mathrm{CO}_{2}\right)$, and hydrogen $\left(\mathrm{H}_{2}\right)$. The dissolved gas analysis (DGA) with insulating oil can be implemented to identify the condition, interpret faults, and provide early warning of some problems inside the transformer. Many DGA techniques are widely used to diagnose significant faults; those techniques include electrical discharges, PD, electrical arcing, and thermal fault [5-8]. Reference [9] proposes the failure analysis based on the dissolved key gas concentration, total dissolved combustible gases (TDCG), and key gas. In [10], the Dörnenburg ratio method was introduced to classify the occurring problem as overheating, electrical discharge, and arcing. In [11], the Rogers ratio method was suggested to identify six fault types occurring in the insulating oil. In [12], IEC gas ratio was proposed to determine PD of high energy, low and high energy discharge, and thermal faults, however, it did not identify failure by paper insulation because it ignored $\mathrm{CO}$ and $\mathrm{CO}_{2}$. In [13-16], the Duval triangle technique was proposed to investigate the causes of faults and failure causes. In [17-21], most of the methods performed DGA with a simple tool to find out the incipient fault. However, it is inconvenient and time-consuming for industrial applications due to the complex analytical process. Hence, artificial intelligence techniques have been proposed to develop more accurate diagnostic tools based on DGA data [22]. In [23-32], some artificial intelligence techniques such as fuzzy logic, artificial neural network and support vector machines have been introduced for fault classification with nearly equal performance without determination of problem severity. Moreover, the artificial neural network technique requires a huge amount of data for training to make it recognize the fault types with less knowledge on the evaluation process. The fuzzy logic method is also an effective method developed to determine the answer, where the boundary is not explicit. It operates by designing the membership function and fuzzy sets appropriated to a specific problem. The most important step is tuning on ranges of the proposed fuzzy sets to obtain the correct answer with logical reason leading to a precise output. Therefore, the fuzzy logic has been adopted for DGA and fault severity analysis in this work.

As a result, this paper adopts and purposes the fuzzy logic approach to three DGA methods: key gas, IEC ratio, and Duval triangle methods to identify possible faults inside the power transformer such as overheat oil and paper, partial discharge, and arcing classified precisely into different ranges of severity. Moreover, the proposed fuzzy logic applied to the key gas method is a novelty used to determine failure index (\%FI) and to identify the severity of faults, facilitates the specification of the proper maintenance actions to prevent the failure. In addition, the proposed combination of IEC ratio and the Duval triangle method is implemented to improve the ability of fault determination up to ten possible faults inside the power transformer. With these proposed fuzzy logic techniques with simulation software, this power transformer diagnostic system is faster, more accurate, and less time-consuming. The DGA test results of 112 power transformers were examined, while two power transformers were thoroughly investigated concerning their internal components.

\section{Dissolved Gas Analysis}

Three DGA methods including key gas, IEC ratio, and the Duval triangle method were used to investigate abnormality and fault inside a power transformer. In this paper, three DGA methods were simultaneously applied together to diagnose different faults within power transformers for more accurate and reliable results. However, before applying the three mentioned methods, one of the key gases must fall into condition " 2 " as a moderate condition of the dissolved key gas concentration limit technique [9] as shown 
in Table 1, otherwise, the fault investigation will not be requested. The dissolved key gas concentration limit technique can identify the severity of faults as good, moderate, poor, and bad condition.

Table 1. Dissolved key gas concentration and condition classification.

\begin{tabular}{ccccccccc}
\hline \multirow{2}{*}{ Condition } & \multicolumn{7}{c}{ Dissolved Key Gas Concentration Limit (ppm) } \\
\cline { 3 - 9 } & & $\mathbf{H}_{\mathbf{2}}$ & $\mathbf{C H}_{\mathbf{4}}$ & $\mathbf{C}_{\mathbf{2}} \mathbf{H}_{\mathbf{2}}$ & $\mathbf{C}_{\mathbf{2}} \mathbf{H}_{\mathbf{4}}$ & $\mathbf{C}_{\mathbf{2}} \mathbf{H}_{\mathbf{6}}$ & $\mathbf{C O}$ & $\mathbf{C O}_{\mathbf{2}}$ \\
\hline 1 & good & $0-100$ & $0-120$ & $0-1$ & $0-50$ & $0-65$ & $0-350$ & $0-2500$ \\
2 & moderate & $101-700$ & $121-400$ & $2-9$ & $51-100$ & $66-100$ & $351-570$ & $2500-4000$ \\
3 & poor & $701-1800$ & $401-1000$ & $10-35$ & $101-200$ & $101-150$ & $571-1400$ & $4001-10,000$ \\
4 & bad & $>1800$ & $>1000$ & $>35$ & $>200$ & $>150$ & $>1400$ & $>10,000$ \\
\hline
\end{tabular}

\subsection{Key Gas Analysis}

The key gas method [9] was used to identify faults inside the power transformer. Key gases included $\mathrm{H}_{2}, \mathrm{C}_{2} \mathrm{H}_{6}, \mathrm{C}_{2} \mathrm{H}_{2}, \mathrm{C}_{2} \mathrm{H}_{4}, \mathrm{CH}_{4}, \mathrm{CO}$, and $\mathrm{CO}_{2}$. Pairs of key gases indicated four types of faults, as shown in Table 2, such as overheat cellulose, overheat oil, electrical arcing, and PD.

Table 2. Fault identification using the key gas method.

\begin{tabular}{ccc}
\hline Pair No. & Pair of Key Gases & Fault Type \\
\hline 1 & $\mathrm{CO}$ and $\mathrm{CO}_{2}$ & overheat cellulose \\
2 & $\mathrm{C}_{2} \mathrm{H}_{4}$ and $\mathrm{C}_{2} \mathrm{H}_{6}$ & overheat oil \\
3 & $\mathrm{CH}_{4}$ and $\mathrm{H}_{2}$ & arcing \\
4 & $\mathrm{C}_{2} \mathrm{H}_{2}$ and $\mathrm{H}_{2}$ & PD \\
\hline
\end{tabular}

\subsection{IEC Ratio Method}

IEC ratio method $[11,13]$ applies three gas ratios $C_{1}, C_{2}$, and $C_{3}$, as written in Equation (1). The ranges of each ratio are specified taking into account different types of faults, including $\mathrm{PD}$, low energy discharge, high energy discharge, thermal fault temperature lower than $300{ }^{\circ} \mathrm{C}$, thermal fault between 300 to $700^{\circ} \mathrm{C}$, and thermal fault temperature greater $700{ }^{\circ} \mathrm{C}$. The ranges and faults are expressed in Table 3.

$$
\mathrm{C}_{1}=\frac{\mathrm{C}_{2} \mathrm{H}_{2}}{\mathrm{C}_{2} \mathrm{H}_{4}}, \mathrm{C}_{2}=\frac{\mathrm{CH}_{4}}{\mathrm{H}_{2}}, \mathrm{C}_{3}=\frac{\mathrm{C}_{2} \mathrm{H}_{4}}{\mathrm{C}_{2} \mathrm{H}_{6}}
$$

Table 3. Fault Identification Using IEC Ratio Method.

\begin{tabular}{cccc}
\hline $\mathrm{C}_{\mathbf{1}}$ & $\mathrm{C}_{\mathbf{2}}$ & $\mathrm{C}_{\mathbf{3}}$ & Fault Type \\
\hline$<0.1$ & $0.1-1$ & $<0.1,0.1-1$ & PD1; PD of low energy \\
$<0.1$ & $<0.1$ & $<0.1,0.1-1$ & PD2; PD of high energy \\
$0.1-1$ & $<0.1$ & $<0.1,0.1-1$ & $\mathrm{D} 1$; discharge of low energy \\
$>3$ & $0.1-1$ & $1-3$ & $\mathrm{D} 2$; discharge of high energy \\
$<0.1$ & $0.1-1$ & $1-3,>3$ & $\mathrm{~T} 1-1$; thermal fault $\mathrm{T}<150^{\circ} \mathrm{C}$ \\
$<0.1$ & $1-3$ & $<0.1,0.1-1$ & $\mathrm{~T} 1-2 ;$ thermal fault $150<\mathrm{T}<300^{\circ} \mathrm{C}$ \\
$<0.1$ & $1-3$ & $1-3$ & $\mathrm{~T} 2 ;$ thermal fault $300<\mathrm{T}<700{ }^{\circ} \mathrm{C}$ \\
$<0.1$ & $1-3$ & $>3$ & $\mathrm{~T} 3$; thermal fault $\mathrm{T}>700^{\circ} \mathrm{C}$ \\
$<0.1$ & $0.1-1$ & $<1$ & normal \\
\hline
\end{tabular}

\subsection{Duval Triangle Method}

The conventional Duval triangle method [13-16] applies only three gases, which are $\mathrm{CH}_{4}, \mathrm{C}_{2} \mathrm{H}_{4}$, and $\mathrm{C}_{2} \mathrm{H}_{2}$, for determining faults in the transformer by using the percentages of $\% \mathrm{CH}_{4}, \% \mathrm{C}_{2} \mathrm{H}_{4}$, and $\% \mathrm{C}_{2} \mathrm{H}_{2}$ as written in Equation (2). The coordination of the three percentages is then plotted on the Duval triangle as presented in Figure 1. For example, 
$\% \mathrm{CH}_{4}$ is firstly marked along the left-axis while $\% \mathrm{C}_{2} \mathrm{H}_{4}$ is then marked along the right-axis. Finally, $\% \mathrm{C}_{2} \mathrm{H}_{2}$ is marked along the $x$-axis. The coordination of $\% \mathrm{CH}_{4},{ }_{0} \mathrm{C}_{2} \mathrm{H}_{4}$ and $\% \mathrm{C}_{2} \mathrm{H}_{2}$ are plotted together to obtain the type of failures.

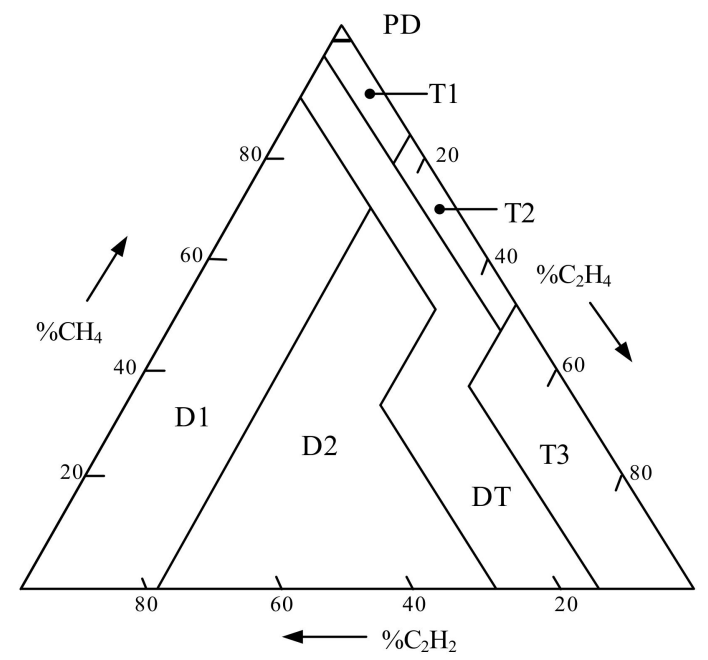

Figure 1. Conventional Duval Triangle.

The area in the Duval triangle is divided into seven zones identifying seven faults such as corona $\mathrm{PD}$, low energy discharge, high energy discharge, thermal fault temperature less than $300{ }^{\circ} \mathrm{C}$, thermal fault temperature between 300 to $700{ }^{\circ} \mathrm{C}$, thermal fault temperature greater than $700{ }^{\circ} \mathrm{C}$, and lastly, mixed thermal and electrical fault as illustrated in Table 4 . This method provides highly accurate results. However, the technique ignores $\mathrm{H}_{2}$ and $\mathrm{C}_{2} \mathrm{H}_{6}$, which limits its ability in fault detection when the faults have progressively formed. Consequently, the key gas and IEC method are also needed.

$$
\% \mathrm{CH}_{4}=\frac{\mathrm{CH}_{4}}{\left(\mathrm{CH}_{4}+\mathrm{C}_{2} \mathrm{H}_{2}+\mathrm{C}_{2} \mathrm{H}_{4}\right)} \times 100, \% \mathrm{C}_{2} \mathrm{H}_{2}=\frac{\mathrm{C}_{2} \mathrm{H}_{2}}{\left(\mathrm{CH}_{4}+\mathrm{C}_{2} \mathrm{H}_{2}+\mathrm{C}_{2} \mathrm{H}_{4}\right)} \times 100, \% \mathrm{C}_{2} \mathrm{H}_{4}=\frac{\mathrm{C}_{2} \mathrm{H}_{4}}{\left(\mathrm{CH}_{4}+\mathrm{C}_{2} \mathrm{H}_{2}+\mathrm{C}_{2} \mathrm{H}_{4}\right)} \times 100
$$

Table 4. Fault identification using Duval triangle method.

\begin{tabular}{cc}
\hline Failure & Fault \\
\hline PD & corona PD \\
D1 & low energy discharge \\
D2 & high energy discharge \\
T1 & thermal fault $\mathrm{T}<300^{\circ} \mathrm{C}$ \\
T2 & thermal fault $300<\mathrm{T}<700^{\circ} \mathrm{C}$ \\
T3 & thermal fault $\mathrm{T}>700^{\circ} \mathrm{C}$ \\
DT & mixed thermal and electrical fault \\
\hline
\end{tabular}

\section{Fuzzy Logic for Insulating Oil Condition Assessment}

The fuzzy logic approach is a computerized calculation tool [24-27] generally used to simulate expert knowledge, experience, and automatic judgment without human action. In this paper, fuzzy logic was applied with three DGA methods as key gas, IEC gas ratio, and the Duval triangle method to analyze faults inside power transformers. Fuzzy logic based triangular membership function(trimf) was defined in different levels in the fuzzy logic approaches to the IEC gas ratio and Duval triangle method as written in Equation (3), while fuzzy logic-based two-Gaussian membership function (gauss2mf), as written in Equation (4), approaches to the key gas method. The original input of each technique is amount of key gases in ppm. A fuzzy rule-based system is developed to specify faults. The Mamdani fuzzy inference system was applied to differentiate results by eliminating ambiguity. A defuzzifier based center of gravity (COG) method was used to interpret and 
display the results into numbers (i.e., 1, 3, 5, .. ) that were then assigned to different faults (i.e., F1, F2, F3, ... ).

$$
f(x ; a, b, c)=\left\{\begin{array}{c}
0, x \leq a \\
\frac{x-a}{b-a}, a \leq x \leq b \\
\frac{c-x}{c-b}, b \leq x \leq c \\
0, c \leq x
\end{array}\right\},
$$

where $f(x ; a, b, c)$ is the output curve of the trimf, and $x$ is input gases in ppm. The values of parameters $a, b$, and $c$ are specified to identify the range of the triangular membership function.

$$
f(x ; \sigma, c)=e^{\frac{-(x-c)^{2}}{2 \sigma^{2}}}
$$

where $f(x ; \sigma, c)$ is the output curve of the gauss $2 \mathrm{mf}$, and $x$ is input gases in ppm. Similarly, the values of $\sigma$ and $c$ are specified to identify the range of the two Gaussian membership functions.

Defuzzification based on the center of gravity (COG) method was used to determine a defuzzified output as written in Equation (5).

$$
z *=\frac{\int z \mu(z) d z}{\int \mu(z) d z}
$$

where $z$ is the output curve applied for both triangular membership function and two Gaussian functions, $\mu(z)$ is the membership function of the defuzzification, and $z^{*}$ is the defuzzified fuzzy output.

\subsection{Application of a Fuzzy Logic Approach to the Key Gas Method}

In this paper, a combination of the two-Gaussian membership function in Equation (4) was applied to the DGA using the key gas method [9]. The advantage of this method can be explained by the fact that there are overlapping areas, which are applied to identify the percentage of failure index (\%FI). The 3-layer fuzzy logic model with 16 fuzzy rules was proposed and expressed in Figure 2 (left), while the shapes of the 16 fuzzy rules are shown in Figure 2 (right). To obtain a precise result, the input ranges of seven input gases were identified according to Table 2, while four output ranges of the output function were identified in Table 5. The Fuzzy output codes and faults are then determined as written in Table 6. Finally, the proposed defuzzification with COG method in Equation (5) was applied to calculate \%FI, referring to the power transformer condition as written in Table 7 , which can be differentiated into three color bands as red, yellow, and green.
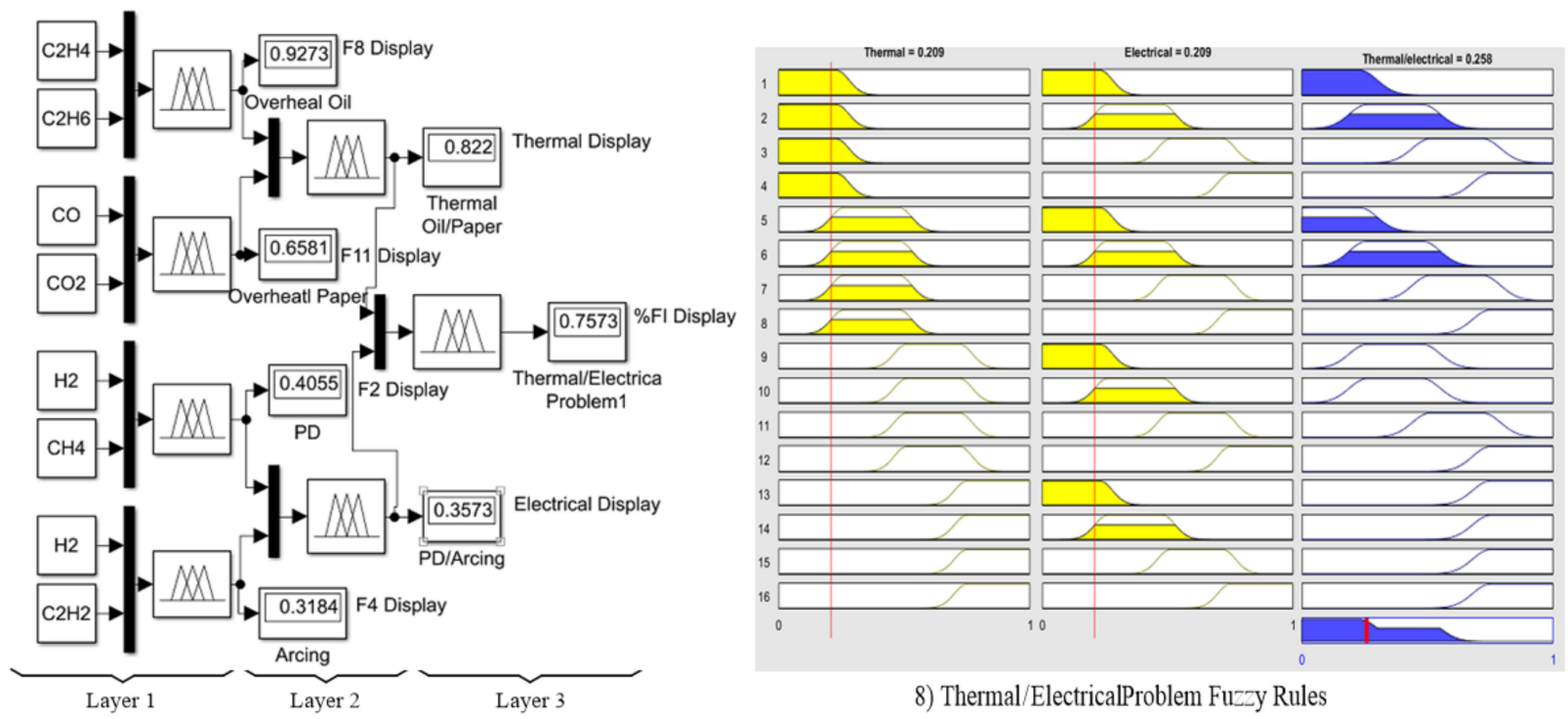

Figure 2. Fuzzy logic model and fuzzy rules for fault identification by using the key gas method. 
Table 5. Output ranges of fuzzy membership function of key gases.

\begin{tabular}{ccccc}
\hline Condition & Good & Accept & Caution & Poor \\
\hline Range & $0-30$ & $20-55$ & $45-75$ & $75-100$ \\
\hline
\end{tabular}

Table 6. Fuzzy output codes and faults using the key gas method.

\begin{tabular}{cc}
\hline Output Code & Fault Identified by Key Gas Method \\
\hline 3 & F2: corona/PD \\
7 & F4: arcing \\
15 & F8: overheat oil \\
19 & F11: overheat cellulose \\
\hline
\end{tabular}

Table 7. \%FI and condition determined by the key gas method.

\begin{tabular}{ccc}
\hline \%FI & Condition & Notified Color \\
\hline $0-25$ & good & green \\
$26-50$ & acceptable & yellow \\
$51-75$ & caution & orange \\
$76-100$ & poor & red \\
\hline
\end{tabular}

Figure 3 shows the two-Gaussian membership fuzzification and defuzzification procedure according to Equations (3) and (5), respectively. In Figure 3 (left), for the first layer, two couples of key gases as $\mathrm{CO}$ and $\mathrm{CO}_{2}, \mathrm{C}_{2} \mathrm{H}_{4}$ and $\mathrm{C}_{2} \mathrm{H}_{6}, \mathrm{CH}_{4}$ and $\mathrm{H}_{2}$, as well as $\mathrm{C}_{2} \mathrm{H}_{2}$ and $\mathrm{H}_{2}$ as the inputs were compared to indicate \%FI, while all four ranges of inputs are defined. In Figure 3 (right), the types of faults in Table 1 as outputs are defuzzified and decoded as F8 representing an overheating oil problem with $92.73 \%$ fault possibility. Similar to the 2nd layer, the couples F2 and F4 as well as F8 and F11 were further compared, resulting to the possibility of $82.2 \%$ as a thermal problem and $35.73 \%$ as an electrical problem. Finally, in the 3 rd layer, $\%$ FI was then calculated as equal to $75.73 \%$.

Two Gaussian membership input function
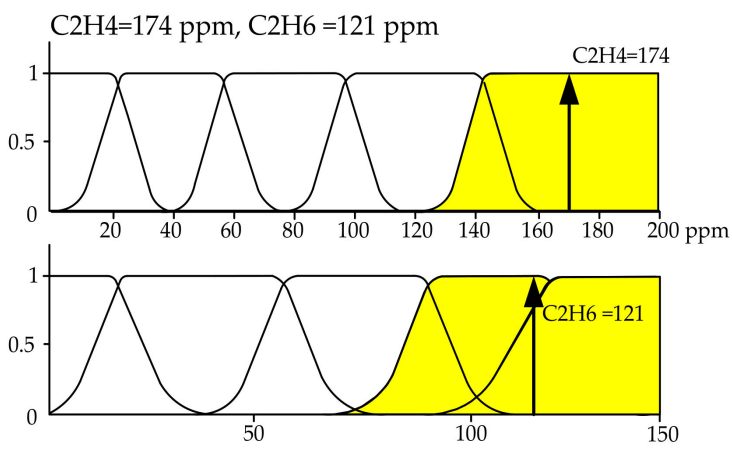

Defuzzification fault by COG method

Key Gas output function

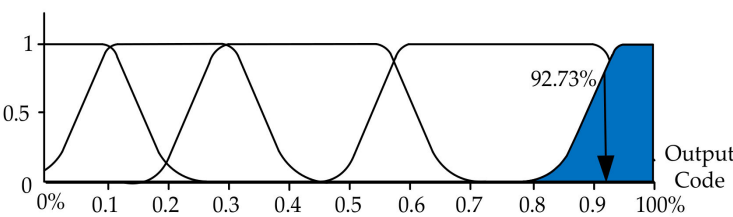

$$
\begin{aligned}
& \mathrm{Z}^{*}=\frac{\int z \mu(z) d z}{\int \mu(z) d z} \\
& \text { COG }=92.73 \% ; \mathrm{F} 8=\text { Overheat Oil }
\end{aligned}
$$

Figure 3. Two-gaussian membership function fuzzification and defuzzification for key gas method.

\subsection{Application of the Fuzzy Logic Approach to IEC Ratio Method}

In this paper, the triangular membership, as in Equation (3) and in Figure 4, was applied to IEC ratio method [13-16] because of the explicit ranges of input conditions as low, medium, high, and very high resulting in easy interpretation. According to the model, ratios $C_{1}, C_{2}$, and $C_{3}$ in Equation (1) were first calculated. Then, the calculated result defined as " $U$ " is the input of this membership function, as shown in Table 8. A single-layer fuzzy model was then applied. Thirty fuzzy rules were proposed to identify possible faults, as shown in Figure 4. The output code is represented by the numbers 1 to 21. Similarly, the 
defuzzification with the COG method is then applied. Nine faults are possible and written in the form of malfunction as given in Table 9.

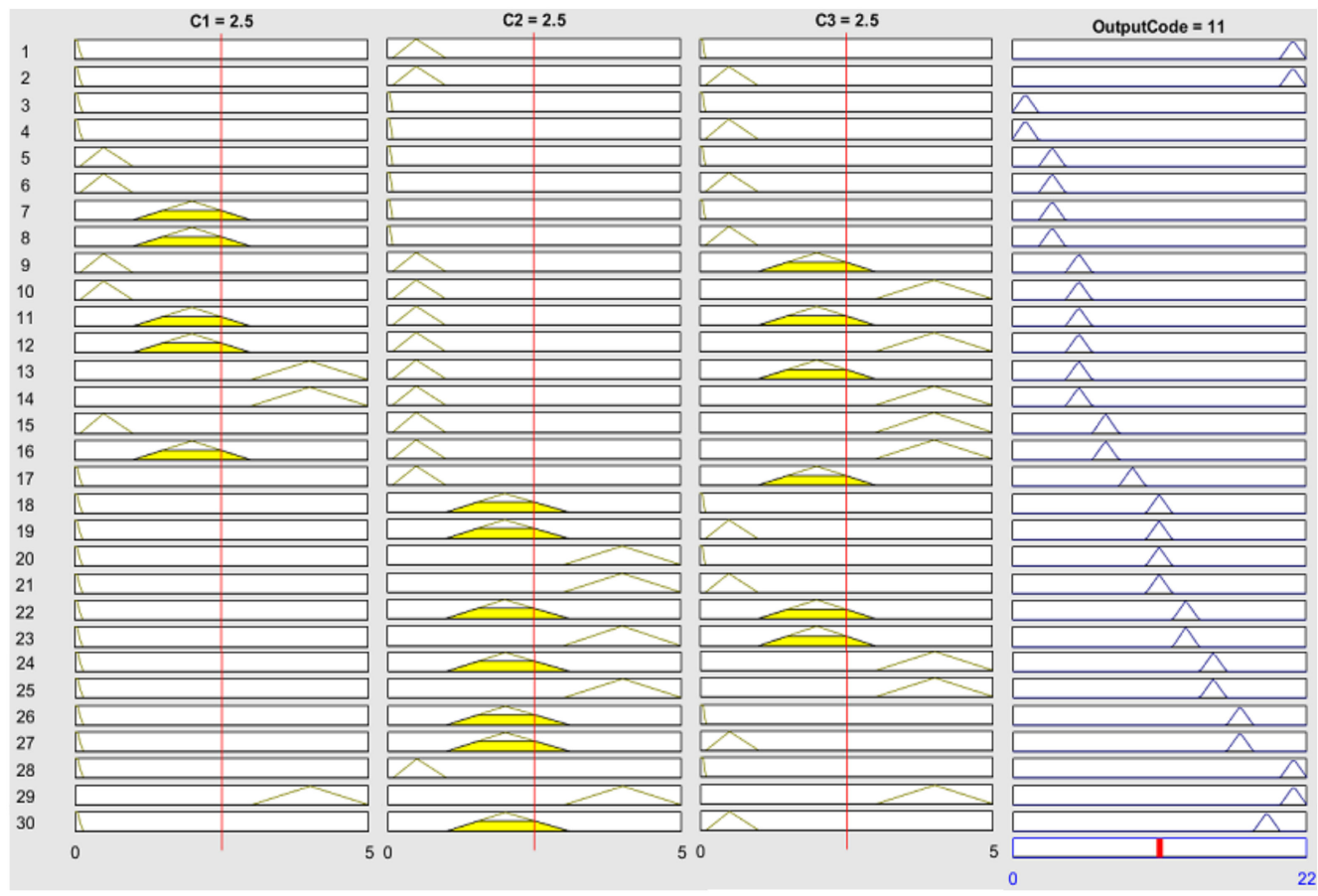

Figure 4. Fuzzy rules for fault identification by using the IEC ratio method.

Table 8. The input range of triangular membership function for the ICE ratio method.

\begin{tabular}{ccccc}
\hline Condition & Low & Medium & High & Very High \\
\hline Range & $U<0.1$ & $0.1 \leq U \leq 1$ & $1 \leq U \leq 3$ & $U>3$ \\
\hline
\end{tabular}

Table 9. Fuzzy output code, function, and fault type using the IEC ratio method.

\begin{tabular}{cc}
\hline Output Code & Fault Identified by IEC Three-Ratio Method \\
\hline 1 & F1: PD of low energy (PD1-1) \\
3 & F2: PD of high energy (PD1-2) \\
5 & F3: low energy discharge (D1-1) \\
7 & F4: high energy discharge (D1-2) \\
9 & F5: thermal fault $\mathrm{T}<150{ }^{\circ} \mathrm{C}(\mathrm{T} 1-1)$ \\
11 & F6: thermal fault $150<\mathrm{T}<300^{\circ} \mathrm{C}(\mathrm{T} 1-2)$ \\
13 & F7: thermal fault $300<\mathrm{T}<700{ }^{\circ} \mathrm{C}(\mathrm{T} 2)$ \\
15 & F8: thermal fault $\mathrm{T}>700^{\circ} \mathrm{C}(\mathrm{T} 3)$ \\
21 & F11: normal \\
\hline
\end{tabular}

For the IEC Ratio method, Figure 5 shows the first layer of triangle membership function fuzzification and defuzzification procedure according to Equations (3) and (5), respectively. In Figure 5 (left), ratios $C_{1}=0, C_{2}=3$, and $C_{3}=1.4$ were calculated by using Equation (1) and represented as inputs in Equation (3). The four ranges of each input were defined, as shown in Figure 5 (left). The types of faults as output are defuzzified as equal to $59 \%$ and decoded as F7 representing thermal fault problem $\left(\mathrm{T} 2 ; 300<\mathrm{T}<700{ }^{\circ} \mathrm{C}\right)$ as written in Figure 5 (right). 

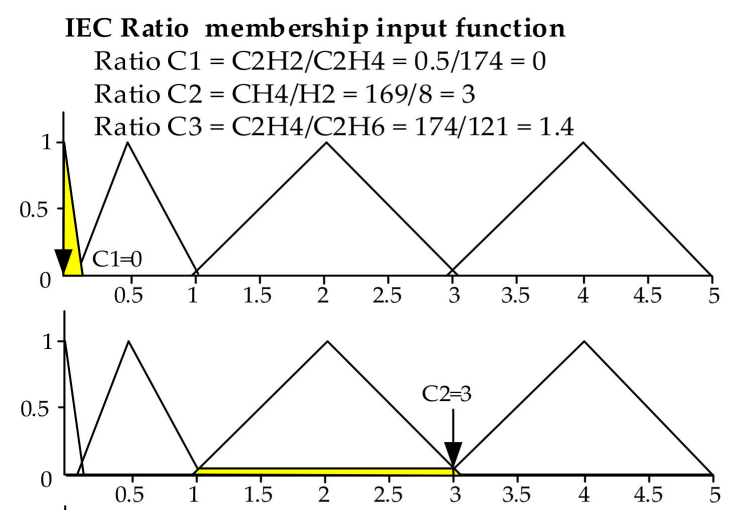

\section{Defuzzification fault by COG method}

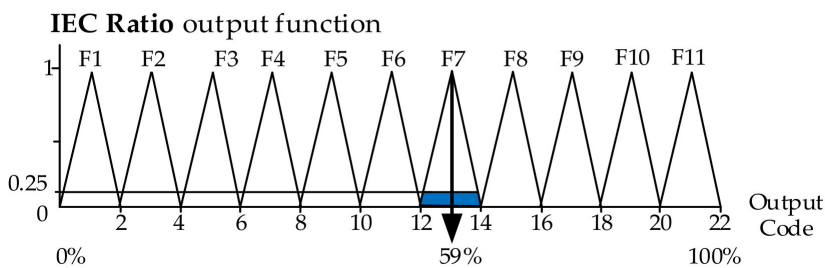

$0 \%$

$$
\begin{aligned}
& \mathrm{z}^{*}=\frac{\int z \mu(z) d z}{\int \mu(z) d z} \\
& \mathrm{COG}=\frac{(54.545 \times 0)+(55 \times 0.25)+(63 \times 0.25)+(63.636 \times 0)}{(0+0.25+0.25+0)}
\end{aligned}
$$

$\mathrm{COG}=59 \%=\mathrm{F} 7=$ Thermal fault $300<\mathrm{T}<700^{\circ} \mathrm{C}$

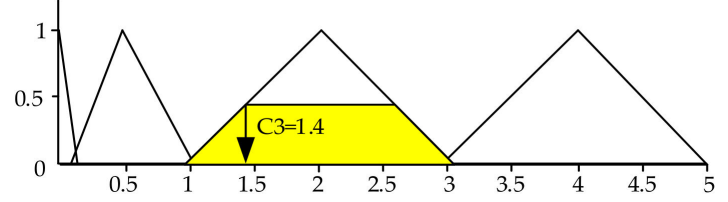

Figure 5. Triangular membership function fuzzification and defuzzification for the IEC ratio method.

\subsection{Fuzzy Logic with Duval Triangle Method}

The triangular membership function is applied to the Duval triangle method [11-14] because of the explicit ranges of the input with the most simple output code interpretation, as written in Table 10 . The percentages of ratio $\% \mathrm{CH}_{4},{ }_{0} \mathrm{C}_{2} \mathrm{H}_{4}$, and $\% \mathrm{C}_{2} \mathrm{H}_{2}$ defined as $\mathrm{Z}, \mathrm{P}$, $\mathrm{S}$ parameters classified in different zones as written in Equation (6) are the inputs of the membership function for plotting in the Duval triangle as presented in Figure 6. Similarly, a single-layer fuzzy model was applied. Sixty fuzzy rules were identified for possible faults, as shown in Figure 7. Similarly, the output code was represented by numbers (1 to 21). The defuzzification with COG method was then applied. The eight fault types identified by the Duval triangle method are written in Table 10.

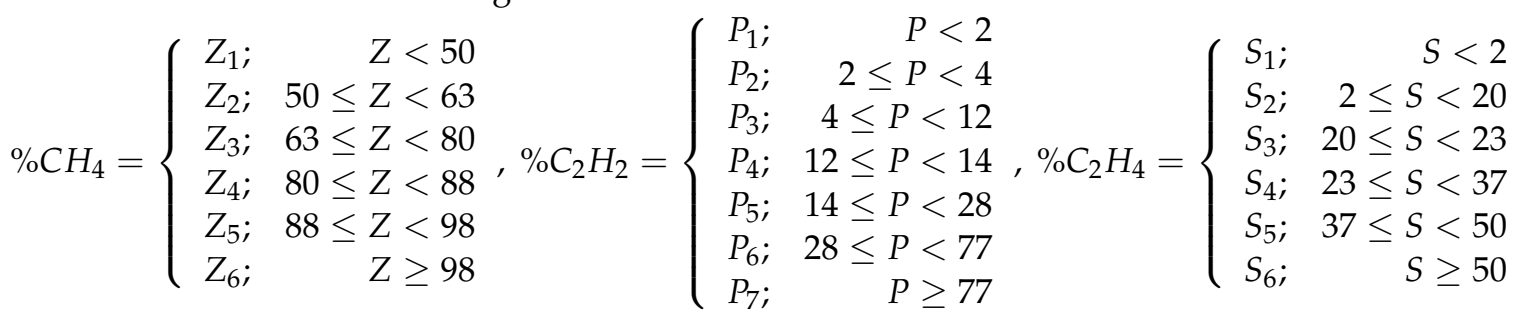

Table 10. Fuzzy output code, function and fault type using Duval triangle method.

\begin{tabular}{cc}
\hline Output Code & Fault Identified by Duval Triangle Method \\
\hline 3 & F2: corona/PD \\
5 & F3: low energy discharge (D1) \\
7 & F4: high energy discharge (D2) \\
11 & F6: low thermal fault $\mathrm{T}<300^{\circ} \mathrm{C}(\mathrm{T} 1)$ \\
13 & F7: medium thermal fault $300<\mathrm{T}<700^{\circ} \mathrm{C}(\mathrm{T} 2)$ \\
15 & F8: high thermal fault $\mathrm{T}>700^{\circ} \mathrm{C}(\mathrm{T} 3)$ \\
17 & F9: mixed thermal and electrical fault (DT) \\
21 & F11: normal \\
\hline
\end{tabular}




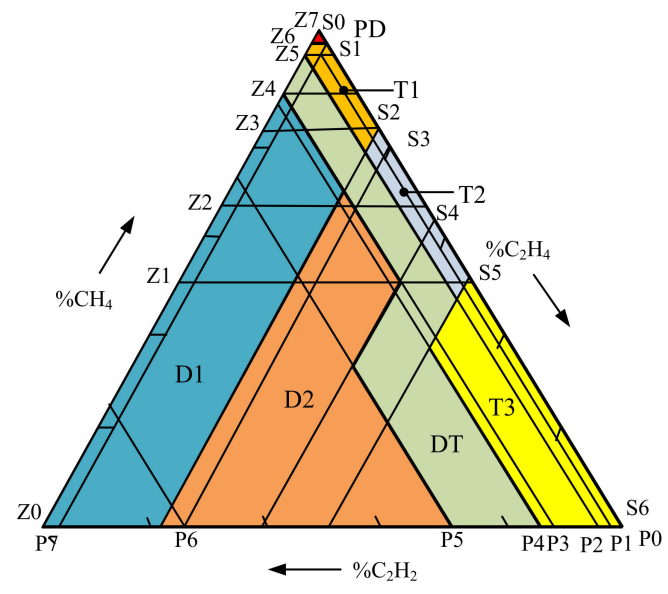

Figure 6. Fuzzy Logic Zoning in Duval Triangle.
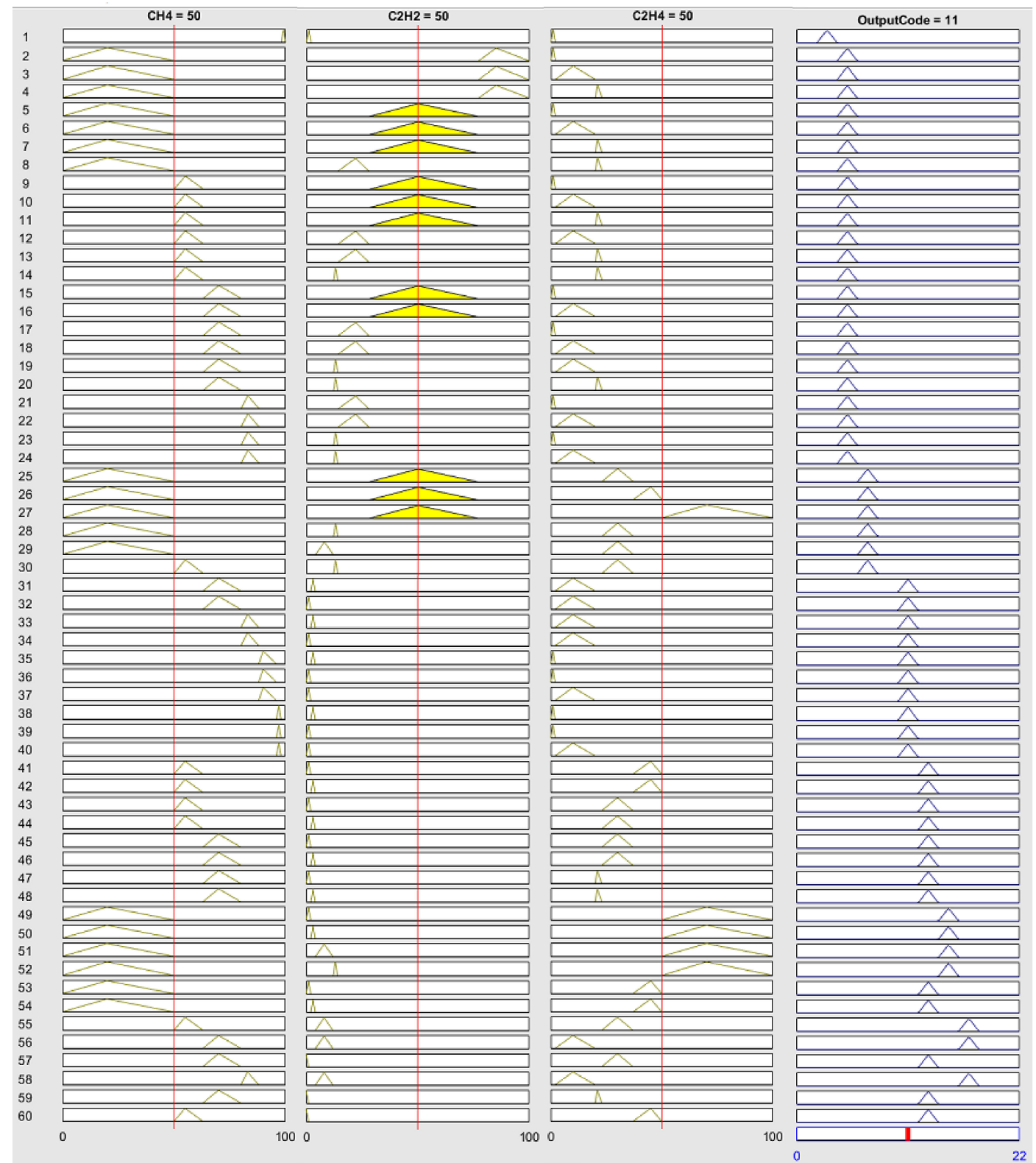

Figure 7. Fuzzy rules for fault identification by using the Duval triangle method. 
Figure 7 shows the fuzzy logic fuzzification and defuzzification procedure for the Duval triangle method by using Equations (3) and (5), respectively. The $\% \mathrm{CH}_{4}, \% \mathrm{C}_{2} \mathrm{H}_{4}$, and $\% \mathrm{C}_{2} \mathrm{H}_{2}$ were calculated as equal to 20.44 , and $21.65,58.35 \%$, which are defined as $\mathrm{Z}, \mathrm{P}$, $\mathrm{S}$ parameters. The ranges of $\mathrm{Z}, \mathrm{P}, \mathrm{S}$ in Equation (6) are also drawn in Figure 8 (left), while the COG was calculated by using fuzzy logic defuzzification and equal to $28.12 \%$ as shown in Figure 8 (right), which falls into F3 decoded to D1 as the discharge of low energy.

\section{Triangle membership input function}
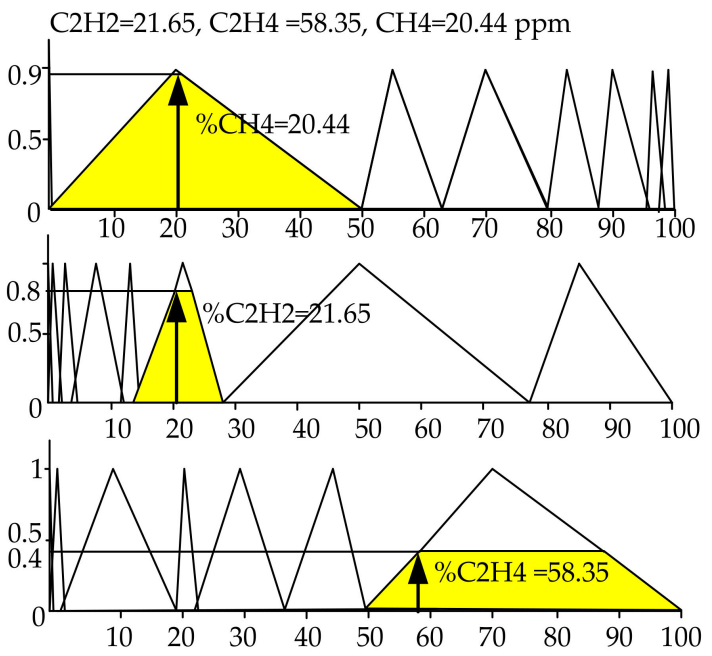

Defuzzification fault by COG method

Duval Triangle output function

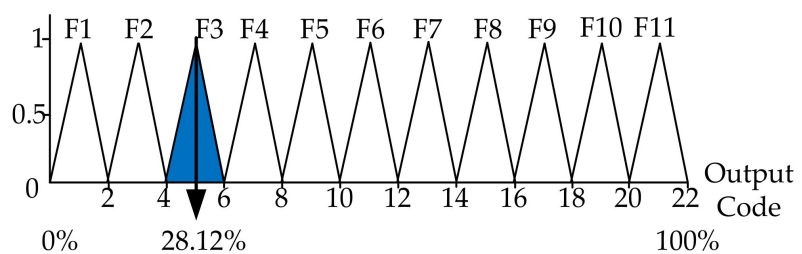

$\mathrm{COG}=\frac{(20.44 \times 0.9)+(21.65 \times 0.8)+(58.35 \times 0.4)}{(0.9+0.8+0.4)}$

$\mathrm{COG}=28.12 \%$

$=\mathrm{F} 3=\mathrm{D} 1$; Discharge of low energy

Figure 8. Triangular membership function fuzzification and defuzzification for the Duval triangle method.

\subsection{Defuzzified Faults from Three Fuzzy Logic Methods}

The proposed defuzzified codes from 1-21, representing eleven faults from three fuzzy logic methods and the key gas, IEC Ratio, and the Duval triangle method were compared, as shown in Figure 9. For example, the defuzzified values between range 2-4 shows the faults as PD1-2 as the partial discharge of high energy density, exactly determined by all three methods. All methods should be simultaneously applied to precisely identify the failure inside the power transformer.

\section{Failure}

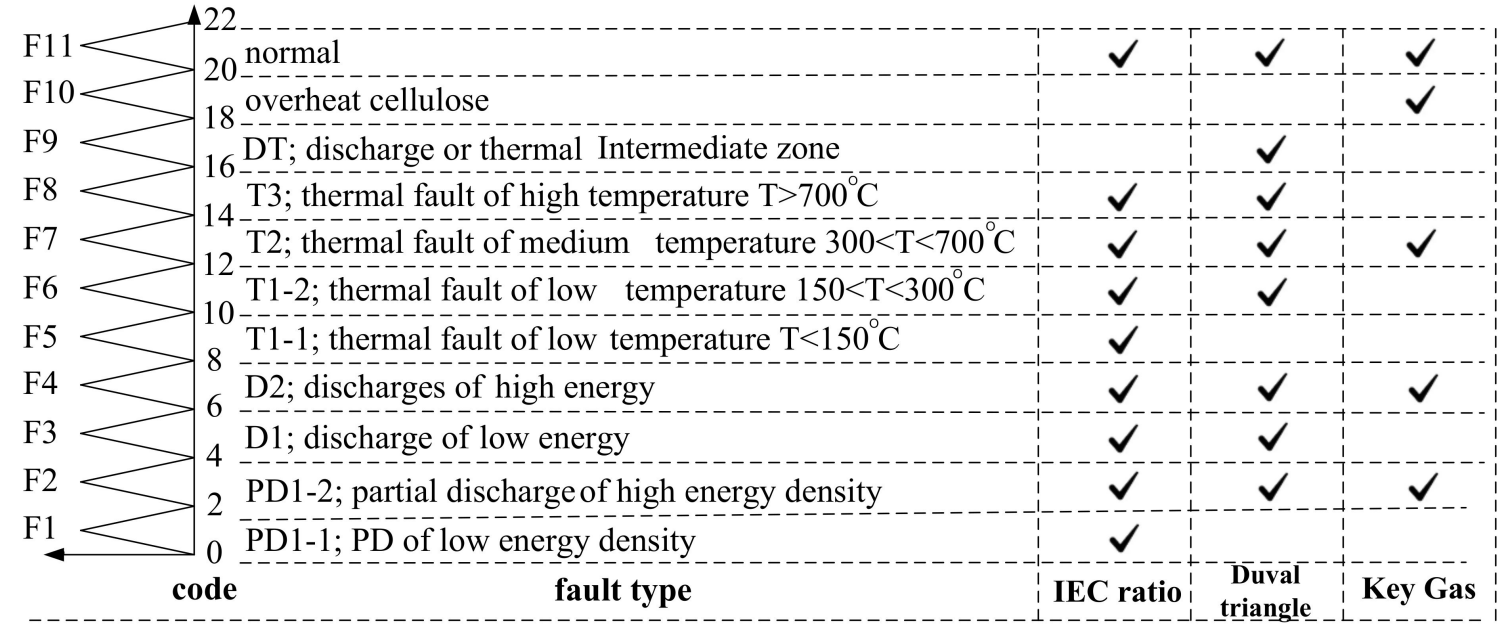

Figure 9. Fault types and fuzzy logic outputs. 


\section{Results and Discussions}

\subsection{Fuzzy Logic Implementation to Practical Two Un-Tanked Power Transformers}

DGA results of two power transformers named as TR1 and TR2 obtained from certified DGA laboratory with ratings $115 / 69 \mathrm{kV}, 15 \mathrm{MVA}$ and $22 \mathrm{kV} / 416 \mathrm{~V}, 3 \mathrm{MVA}$, respectively with un-tanked investigation after failure [18] were analyzed and interpreted for problems occurring within paper and oil insulation of these transformers, as given in Table 11. The faults identified by three fuzzy logic approaches are shown in Table 12. All methods by Fuzzy Logic confirmed the arcing inside the power transformer recognized from the abnormal amount of $\mathrm{C}_{2} \mathrm{H}_{2}$, as well as obvious pictures from the internal investigation, as shown in Figures 10 and 11.

Table 11. Input gases (ppm) of TR1 and TR2.

\begin{tabular}{cccccccc}
\hline \multirow{2}{*}{ Case } & \multicolumn{7}{c}{ Quantity of Gases (ppm) } \\
\cline { 2 - 8 } & $\mathbf{H}_{\mathbf{2}}$ & $\mathrm{CO}_{\mathbf{2}}$ & $\mathbf{C O}$ & $\mathbf{C}_{\mathbf{2}} \mathbf{H}_{\mathbf{4}}$ & $\mathrm{C}_{\mathbf{2}} \mathbf{H}_{\mathbf{6}}$ & $\mathbf{C H}_{\mathbf{4}}$ & $\mathbf{C}_{\mathbf{2}} \mathbf{H}_{\mathbf{2}}$ \\
\hline TR1 & 602 & 112 & 298 & 97 & 6 & 90 & 262 \\
TR2 & 5383 & 3173 & 465 & 30,787 & 4402 & 19,231 & 361 \\
\hline
\end{tabular}

Table 12. Fuzzy logic results of TR1 and TR2.

\begin{tabular}{ccccc}
\hline Case & \%FI & Key Gas & IEC Ratio & Duval Triangle \\
\hline TR1 & 87.1 & arcing and OVH & D2; discharge of \\
oil & high energy \\
TR2 & 86.8 & arcing and PD & $\begin{array}{c}\text { T2; thermal fault } \\
\text { T }>700^{\circ} \mathrm{C}\end{array}$ & $\begin{array}{c}\text { T2; thermal fault } \\
\mathrm{T}>700^{\circ} \mathrm{C}\end{array}$ \\
\hline
\end{tabular}
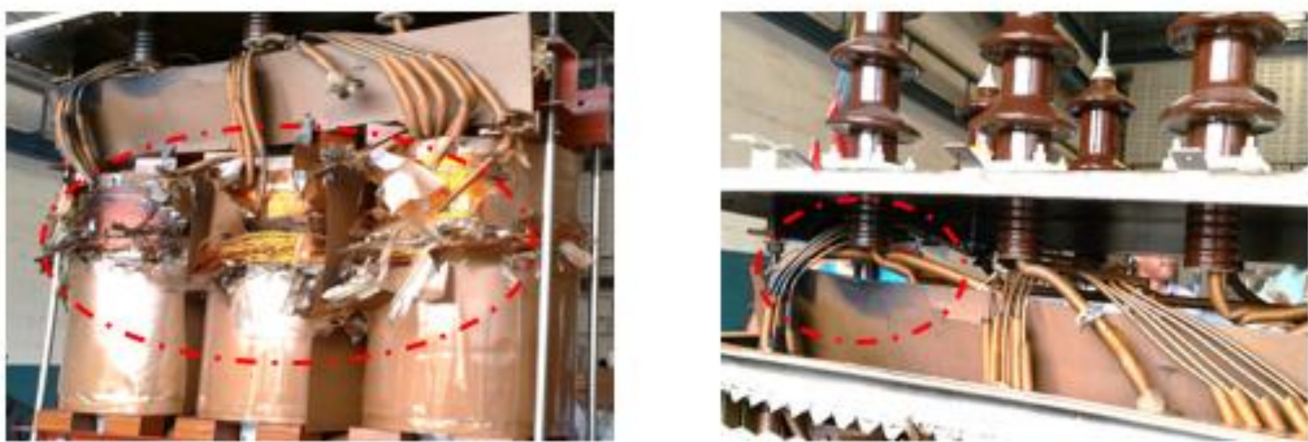

Figure 10. Severe damage of winding due to arcing inside TR1, 115/69 kV, 15 MVA.
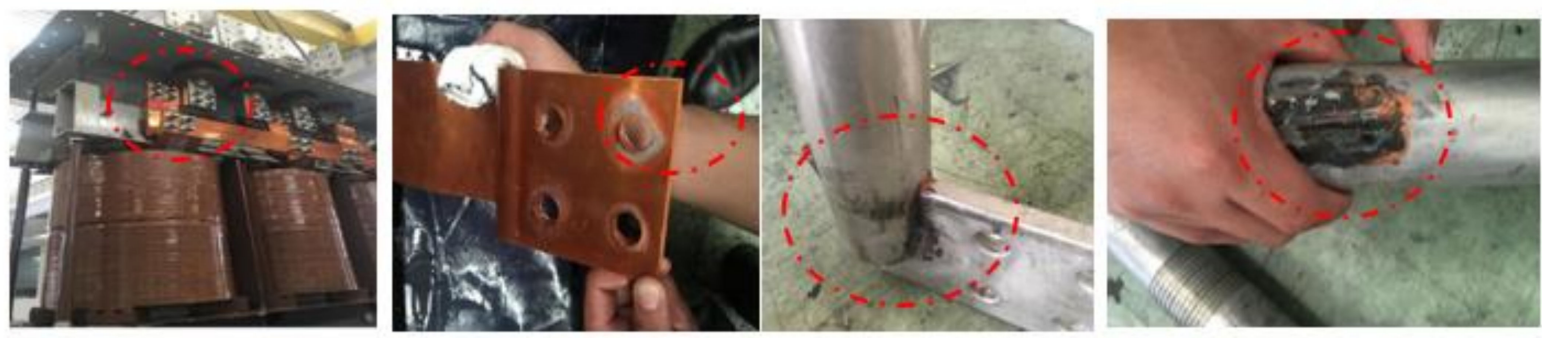

Figure 11. Arcing due to loosened bolts and nuts inside TR2, $22 \mathrm{kV} / 416 \mathrm{~V}, 3 \mathrm{MVA}$.

\subsection{Fuzzy Logic Implementation to 10 Power Transformers}

Similarly, Table 13 shows practical DGA results of additional ten transformers named as TR3 to TR12 obtained from a certified DGA laboratory. By applying the TDCG method, 
TR5 encountered condition " 2 " that a fault could probably occur within the transformer. Transformers TR3 to TR12 (except TR5) encountered condition " 3 " indicating that some faults were identified. Then, the fuzzy logic was further applied to identify the types of defect.

Table 13. Input gases (ppm) from an on-site test with an additional ten power transformers.

\begin{tabular}{|c|c|c|c|c|c|c|c|c|c|}
\hline \multirow{2}{*}{ Case } & \multirow{2}{*}{$\begin{array}{l}\text { kV Rating } \\
{ }^{*} \text { pri/sec/ter }\end{array}$} & \multirow{2}{*}{$\begin{array}{l}\text { MVA Rating } \\
* * \text { ONAN/ONAF }\end{array}$} & \multicolumn{7}{|c|}{ Quantity of Gases (ppm) } \\
\hline & & & $\mathbf{H}_{2}$ & $\mathrm{CH}_{4}$ & $\mathrm{CO}$ & $\mathrm{CO}_{2}$ & $\mathrm{C}_{2} \mathrm{H}_{4}$ & $\mathrm{C}_{2} \mathrm{H}_{6}$ & $\mathrm{C}_{2} \mathrm{H}_{2}$ \\
\hline TR3 & $69 / 12$ & $30 / 40$ & 32 & 36 & 414 & 4408 & 16 & 19 & 2 \\
\hline TR4 & $69 / 12$ & $30 / 40$ & 36 & 79 & 72 & 1686 & 10 & 426 & 0.5 \\
\hline TR5 & $69 / 24$ & $30 / 40$ & 35 & 58 & 91 & 2362 & 8 & 204 & 0.5 \\
\hline TR6 & $69 / 24 / 12$ & $30 / 40$ & 79 & 40 & 502 & 3323 & 33 & 22 & 11.1 \\
\hline TR7 & $69 / 24 / 12$ & $30 / 40$ & 11 & 10 & 232 & 2608 & 44 & 19 & 2 \\
\hline TR8 & $69 / 12$ & $36 / 48 / 60$ & 31 & 134 & 151 & 2532 & 12 & 502 & 1.5 \\
\hline TR9 & $69 / 12$ & $36 / 48 / 60$ & 5 & 85 & 117 & 2129 & 30 & 784 & 0 \\
\hline TR10 & $69 / 12$ & $30 / 40$ & 27 & 0 & 35 & 170 & 739 & 209 & 1224 \\
\hline TR11 & $69 / 12$ & $36 / 48 / 60$ & 70 & 21 & 1094 & 6558 & 4 & 16 & 2.5 \\
\hline TR12 & $69 / 24 / 12$ & $36 / 48 / 60$ & 8 & 169 & 485 & 9760 & 174 & 121 & 0.5 \\
\hline
\end{tabular}

${ }^{*}$ pri/sec/ter means voltage ratings of primary/secondary/tertiary windings. ${ }^{* *}$ ONAN/ONAF are cooling types; i.e., 36/48/60 means ONAN/ONAF/ONAF.

The results of faults such as corona and PD, arcing, overheated oil, overheated cellulose/paper, and \%FI were precisely identified by fuzzy logic with the key gas method as shown in Table 14. Transformer nos. 4, 5, 8, 9, 11, and 12 encountered high severe faults. Similarly, with the fuzzy logic approach to the IEC three-gas ratio and Duval triangle, the results are compared with key gas methods, as shown in Table 15. The results agree well between both analysis methods.

Table 14. Fault identification by the key gas method.

\begin{tabular}{ccccccc}
\hline Case & $\begin{array}{c}\text { F2 } \\
\text { Corona/PD }\end{array}$ & $\begin{array}{c}\text { F4 } \\
\text { Arcing }\end{array}$ & $\begin{array}{c}\text { F8 } \\
\text { Overheat Oil }\end{array}$ & $\begin{array}{c}\text { F11 } \\
\text { Overheat Paper }\end{array}$ & \%FI & Fault Type \\
\hline TR3 & 0.256 & 0.335 & 0.226 & 0.509 & 58.3 & overheat paper \\
TR4 & 0.313 & 0.318 & 0.927 & 0.268 & 86.9 & overheat oil \\
TR5 & 0.283 & 0.318 & 0.927 & 0.325 & 87.1 & overheat oil \\
TR6 & 0.311 & 0.673 & 0.249 & 0.508 & 70.8 & overheat paper \\
TR7 & 0.224 & 0.335 & 0.264 & 0.341 & 36.2 & normal \\
TR8 & 0.361 & 0.326 & 0.927 & 0.336 & 86.9 & overheat oil \\
TR9 & 0.321 & 0.315 & 0.927 & 0.309 & 86.9 & overheat oil \\
TR10 & 0.235 & 0.849 & 0.5 & 0.162 & 70.7 & arcing \\
TR11 & 0.3 & 0.345 & 0.216 & 0.842 & 86.8 & overheat paper \\
TR12 & 0.405 & 0.318 & 0.927 & 0.658 & 87.0 & overheat oil \\
\hline
\end{tabular}

Table 15. Fault identification by key gas, IEC ratio, and Duval triangle method.

\begin{tabular}{cccc}
\hline Case & Key Gas & IEC Ratio & Duval Triangle \\
\hline TR3 & overheat paper & thermal fault, $150<\mathrm{T}<300{ }^{\circ} \mathrm{C}$ & thermal fault, $300<\mathrm{T}<700{ }^{\circ} \mathrm{C}$ \\
TR4 & overheat oil & thermal fault, $150<\mathrm{T}<30{ }^{\circ} \mathrm{C}$ & thermal fault, $\mathrm{T}<300{ }^{\circ} \mathrm{C}$ \\
TR5 & overheat oil & thermal fault, $150<\mathrm{T}<30{ }^{\circ} \mathrm{C}$ & thermal fault, $\mathrm{T}<300{ }^{\circ} \mathrm{C}$ \\
TR6 & overheat paper & discharge of low energy & discharge of high energy \\
TR7 & normal & not analyzed due to normal & not analyzed due to normal \\
TR8 & overheat oil & thermal fault, $150<\mathrm{T}<300{ }^{\circ} \mathrm{C}$ & thermal fault, $\mathrm{T}<300{ }^{\circ} \mathrm{C}$ \\
TR9 & overheat oil & thermal fault, $150<\mathrm{T}<300{ }^{\circ} \mathrm{C}$ & thermal fault, $300<\mathrm{T}<700{ }^{\circ} \mathrm{C}$ \\
TR10 & arcing & thermal fault $150<\mathrm{T}<300{ }^{\circ} \mathrm{C}$ & discharge of high energy \\
TR11 & overheat paper & thermal fault, $300<\mathrm{T}<700{ }^{\circ} \mathrm{C}$ & thermal fault, $\mathrm{T}>700{ }^{\circ} \mathrm{C}$ \\
TR12 & overheat oil & thermal fault, $300<\mathrm{T}<700{ }^{\circ} \mathrm{C}$ & thermal fault, $\mathrm{T}>700{ }^{\circ} \mathrm{C}$ \\
\hline
\end{tabular}




\subsection{Model Validation of the Fuzzy Logic System with Three DGA methods}

This paper proposed a fuzzy logic system for power transformer fault assessment based on the three DGA methods; key gas, IEC ratio, and Duval triangle method were validated with a population of 500 power transformers. The diagnosis DGA of 132 transformers taken from $[30,33]$ as reference cases were first validated with accurate results. Then, DGA results of the total 112 power transformers with rating $115 / 22 \mathrm{kV}$ in subtransmission system of two electrical utilities were further validated with the developed fuzzy logic system. From these additional 112 cases, the raw DGA data of 2 un-tanked transformers is shown in Table 11 to confirm the obtained results with the evidence found, and 10 example cases are shown in Table 13 to demonstrate result consistency. Moreover, the additional raw DGA data of 100 cases were obtained from a certified DGA laboratory, and the fault types of 100 cases were first analyzed with standard diagnosis methods and subsequently used to validate the results from the developed fuzzy logic system. Table 16 presents a comparison of results from the fuzzy logic approach to three DGA standard diagnosis methods. The number of transformers was increased to 244 samples to improve the precision of the assessment.

Table 16. Comparison of results from fuzzy logic approach to three DGA standard diagnosis methods.

\begin{tabular}{|c|c|c|c|c|c|c|c|c|c|}
\hline \multirow{2}{*}{ Fault Type } & \multicolumn{3}{|c|}{ Duval Triangle } & \multicolumn{3}{|c|}{ IEC Ratio } & \multicolumn{3}{|c|}{ Key Gas } \\
\hline & * std. & $* * \mathbf{F L}$ & diff. & * std. & $* * \mathrm{FL}$ & diff. & * std. & $* * \mathbf{F L}$ & diff. \\
\hline normal & 77 & 77 & 0 & 77 & 88 & 11 & 77 & 80 & 3 \\
\hline $\begin{array}{c}\text { overheat celluloseDT; discharge or } \\
\text { thermal }\end{array}$ & 10 & 5 & 5 & & & & 40 & 26 & 14 \\
\hline $\mathrm{T} 3$; thermal fault $\mathrm{T}>700^{\circ} \mathrm{C}$ & 26 & 27 & 1 & 0 & 12 & 12 & & & \\
\hline $\mathrm{T} 2$; thermal fault $300<\mathrm{T}<700^{\circ} \mathrm{C}$ & 24 & 24 & 0 & 17 & 37 & 20 & 41 & 59 & 18 \\
\hline T1-2; thermal fault $150<\mathrm{T}<300{ }^{\circ} \mathrm{C}$ & 16 & 14 & 2 & 14 & 20 & 6 & & & \\
\hline $\mathrm{T} 1-1 ;$ thermal fault $\mathrm{T}<150^{\circ} \mathrm{C}$ & & & & 0 & 2 & 2 & & & \\
\hline D2; discharge of high energy & 56 & 57 & 1 & 16 & 46 & 30 & 72 & 69 & 4 \\
\hline D1; discharge of low energy & 24 & 27 & 3 & 39 & 32 & 7 & & & \\
\hline PD1-2; partial discharge high energy & 11 & 13 & 2 & 2 & 7 & 5 & 14 & 10 & 4 \\
\hline PD1-1; partial discharge low energy & & & & 0 & 0 & 0 & & & \\
\hline unable to identify & 0 & 0 & 0 & 79 & 0 & $\mathrm{n} / \mathrm{a}$ & 0 & 0 & 0 \\
\hline total un-matched units & & & 14 & & & 93 & & & 43 \\
\hline total matched units & & & 229 & & & $\mathrm{n} / \mathrm{a}$ & & & 201 \\
\hline total units & 244 & 244 & 244 & 244 & 244 & 244 & 244 & 244 & 244 \\
\hline error $(\%)$ & & & 5.74 & & & 38.11 & & & 17.63 \\
\hline accuracy $(\%)$ & & & 94.26 & & & 61.89 & & & 82.37 \\
\hline $\begin{array}{c}\text { final accuracy after applying sampling } \\
\text { theory with } 5 \% \text { error }(\%)\end{array}$ & & & 89.54 & & & 58.79 & & & 78.26 \\
\hline
\end{tabular}

"* std." means DGA cases obtained from [30-34] and the laboratory with standard diagnosis methods. "** FL" means DGA analysis using the fuzzy logic system. "diff." means the number of DGA analysis results using the fuzzy logic system were different from reference cases. " $\mathrm{n} / \mathrm{a}$ " means unable to calculate because of an unidentified fault by the IEC method.

In Table 16, the matched and unmated cases, as well as the percentage accuracy and error are given. The percentage error using fuzzy logic based key gas, IEC ratio, and Duval triangle methods was also calculated by dividing the numbers of unmatched units with the total tested units, which were equal to $82.37,61.89$, and $94.26 \%$, resulting in a percentage accuracy of $80.33,69.67$, and $93.85 \%$, respectively, as shown in Table 16 . By applying the sampling theory, the statistical method mentioned in [34] estimated a 5\% output error of the system when 244 data was tested out of 500 samples. The overall accuracy was further calculated by multiplying $95 \%$ accuracy from sampling theory to the obtained percentage accuracy. Lastly, the final percentage accuracy was calculated as $78.26,58.79$, and $89.54 \%$, accordingly. This implied that the required number of tested DGA data should be more than 244 out of the total 500 populations to improve the accuracy with less than $5 \%$ error. 
As presented in Table 16, the fuzzy logic approach with the Duval triangle method yielded the most accurate result with $89.54 \%$. It was also clearly seen that the fuzzy logic approach with IEC ratio method could improve the drawbacks of the standard IEC ratio method as the obtained results agreed well with the Duval triangle method. Consequently, 79 fault types, which were unidentified by the conventional IEC method, were better classified by the fuzzy logic system. Moreover, the fuzzy logic approach to the key gas method was able to evaluate both the percentage of failure index and internal fault determination.

\subsection{Graphical Circle Using Fuzzy Logic Approach to DGA Results for 100 Power Transformers}

A graphical circle was implemented to clearly identify and compare the fault results analyzed by fuzzy logic with three DGA methods when the DGA of 100 power transformers in a utility was investigated. A certified laboratory validated the raw DGA data of these 100 transformers, and the fault types were determined by the standard diagnosis method. In Figures 12 and 13, graphs of a 100 power transformer fleet in Thailand are presented as examples. Figure 12 (left) shows the numbers of four faults as of $\mathrm{PD}, \mathrm{OVH}$ paper, $\mathrm{OVH}$ oil, and arcing, classified by the key gas method using standard diagnosis methods using an excel program. It showed that 15 and 10 transformers encountered $\mathrm{OVH}$ paper and oil, respectively. Whereas in Figure 12 (right), the numbers of four faults analyzed by the key gas method with fuzzy logic are given, which were identical to the results obtained from the standard diagnosis method. This shows that fuzzy logic can be simply applied in an easier and less time-consuming manner. Moreover, with this fuzzy logic approach, each type of fault can be deeply identify the severity of each case confirmed by \%FI. For example, at the outermost circle in Figure 12 (right), among 15 cases of an OVH paper problem with high \%FI, 1 out of 15 was classified as poor. Similarly, 10 cases of an OVH oil problem were classified as high \%FI, while 9 out of 10 were classified as poor condition. In Figure 13 (left) and (right), fuzzy logic was applied to the IEC three-gas ratio and Duval triangle method. The results of these two methods were compared and confirmed almost homogeneously. However, the trend and types of faults could be identified correctly.
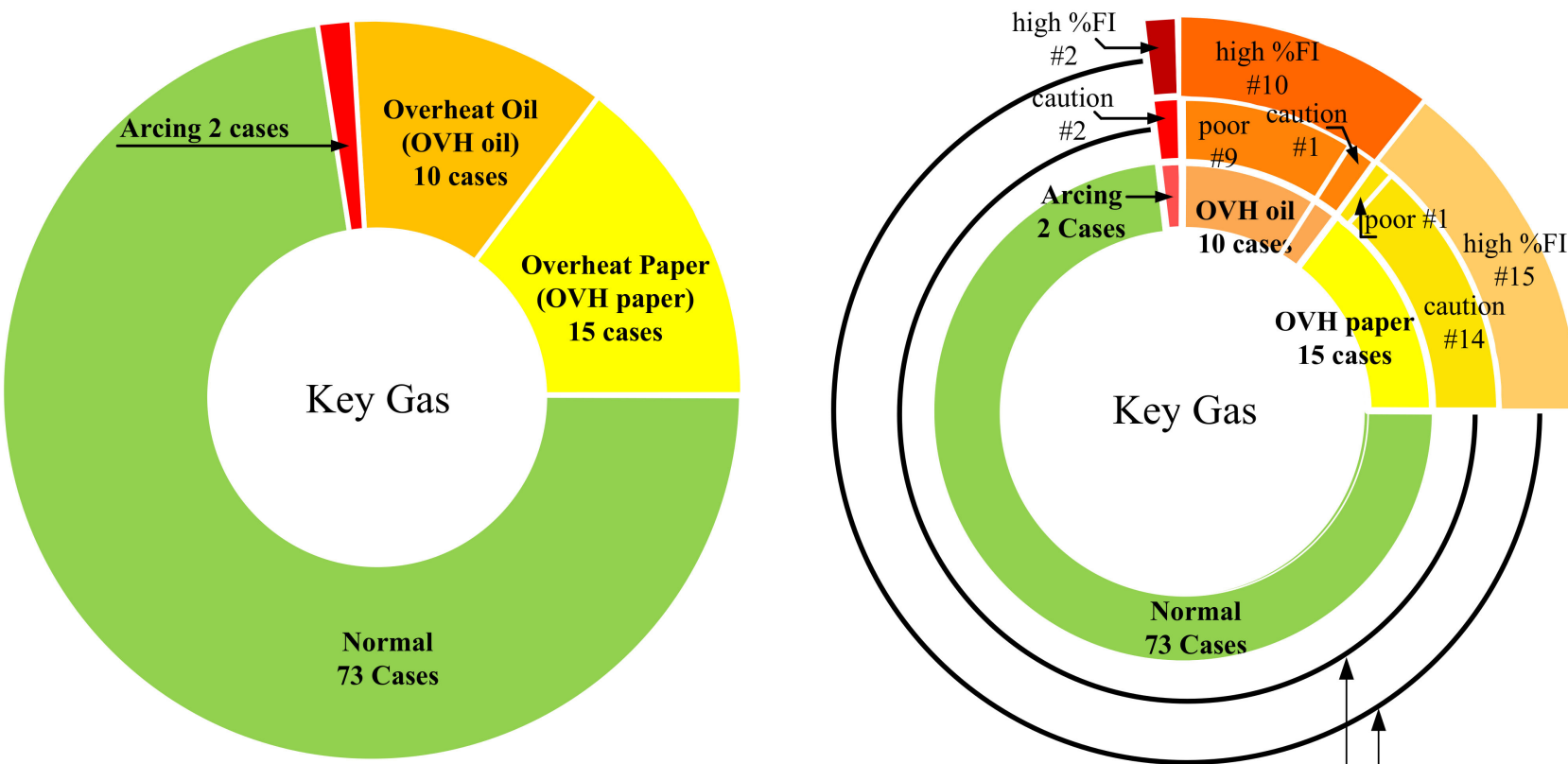

Fault identification by Fuzzy Logic and key gas method

Fault identification by Fuzzy Logic, key gas and \%FI

Figure 12. Fault types analyzed by using fuzzy logic with the key gas method. 


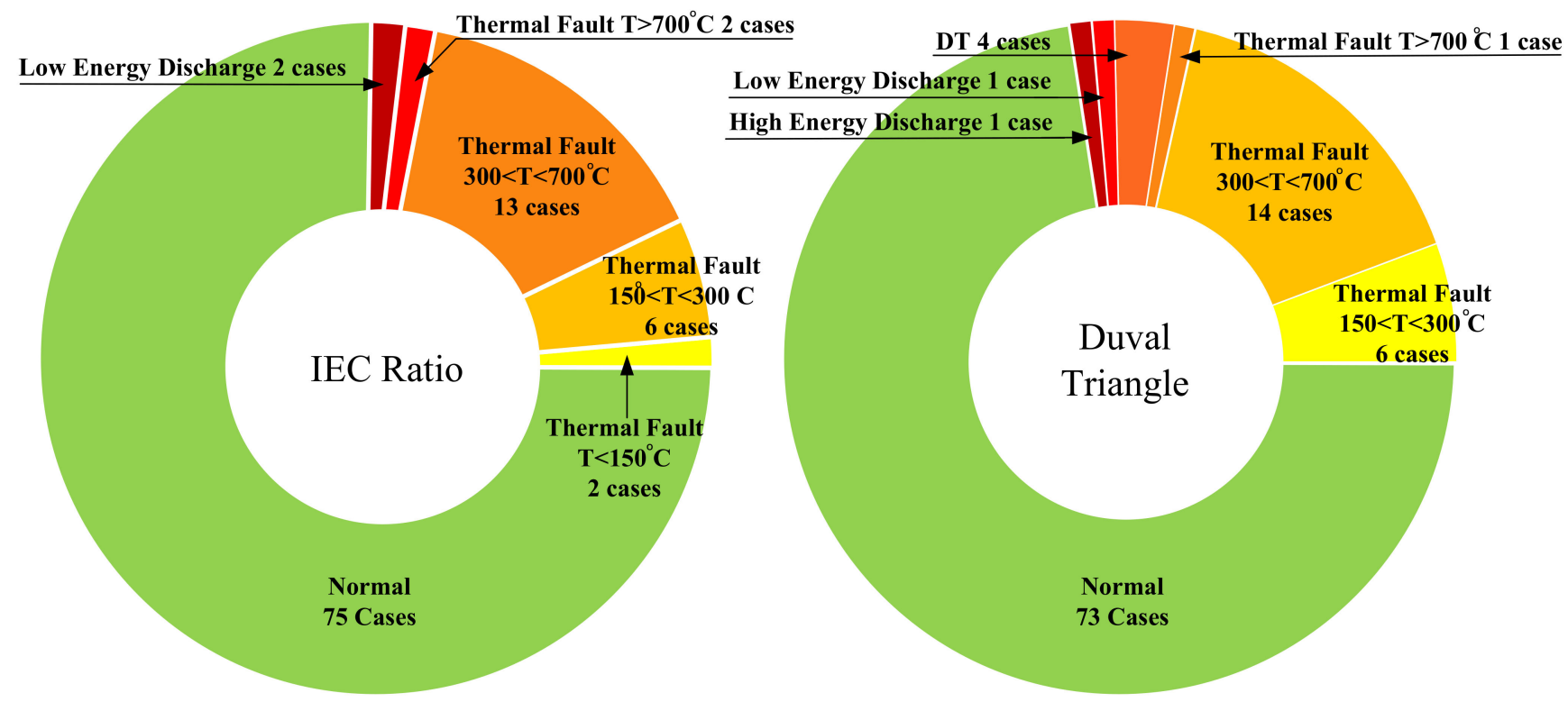

Figure 13. Fault types analyzed by using a fuzzy logic system with IEC ratio and Duval triangle methods.

\subsection{Maintenance Strategy}

The maintenance task and usage strategy together with the inspection interval are recommended to set up the effective maintenance planning to prevent $/ \mathrm{minimize}$ the damage and losses occurring in power transformers and electrical networks. \%FI is used to identify the conditions and the required maintenance tasks as stipulated in Table 17. The four different ranges are classified into good, acceptable, caution, and poor condition by a sensitivity check of the power transformer population, as well as experiences of the research group and utility's experts. The maintenance task and usage strategies are mentioned accordingly.

Table 17. Maintenance tasks and usage strategies corresponding to the accessed conditions.

\begin{tabular}{|c|c|c|}
\hline$\%$ FI & Condition & Maintenance Task and Usage Strategies \\
\hline $0-25$ & good & $\begin{array}{c}\text { time-based maintenance: routine visual inspection, dielectric breakdown voltage test, DGA, PD } \\
\text { measurement at regular interval (usually once in } 2 \text { or } 3 \text { years) }\end{array}$ \\
\hline $26-50$ & acceptable & $\begin{array}{l}\text { time-based maintenance: routine visual inspection, dielectric breakdown voltage test, DGA, PD } \\
\text { measurement, electrical test such as turn ratio, power factor, polarization index (usually once a year) }\end{array}$ \\
\hline $51-75$ & caution & $\begin{array}{l}\text { condition-based maintenance: full electrical and insulating oil test, DGA, PD measurement with } \\
\text { localization, shutdown planning for investigation }\end{array}$ \\
\hline 76-100 & poor & $\begin{array}{l}\text { shutdown and corrective maintenance: condition monitoring, root caused analysis, maintenance } \\
\text { setup and execution, recondition monitoring, usage decision making }\end{array}$ \\
\hline
\end{tabular}

\section{Conclusions}

A fuzzy logic approach to three DGA methods; key gas method, IEC three-gas ratio and Duval triangle methods were used to evaluate the condition of power transformers by the percentage of the failure index and the internal fault determination. Moreover, the fuzzy logic with the key gas approach could calculate \%FI and identify problems that may occur inside power transformers, while the IEC three-gas ratio and Duval triangle can confirm the problems in different failure types covering all possibilities inside power transformers. Then, the fuzzy logic applied to DGA results of two transformers were evaluated and practically confirmed by an un-tanked power transformer showing arcing at the core in both cases. In addition, the DGA results of ten transformers were further evaluated. The fuzzy logic approach with three DGA methods results were shown and 
compared. The condition and the internal problems of power transformers could be clearly identified. The graphic circle was introduced to compare the analyzed results of a large number of power transformers. Then, the severity of faults inside the transformers could be deeply identified in terms of the percentage of failure index. This fuzzy logic is a smart, accurate tool for automatically identifying faults occurring within transformers. Then, the recommended maintenance strategy and time interval were proposed for effective planning to minimize the catastrophic damage, which could occur with power transformers and their networks. Finally, the fuzzy logic simulation software with proposed techniques was developed as a low cost, easy, accurate, and less time-consuming tool.

Author Contributions: Conceptualization, C.S., N.P. and T.S.; methodology, C.S., N.P. and T.S.; formal analysis, C.S., N.P. and T.S.; investigation, C.S., N.P. and T.S.; resources, N.P. and T.S.; data curation, N.P.; writing — original draft preparation, C.S. and N.P.; writing—review and editing, C.S. and T.S.; supervision, C.S. and T.S.; project administration, C.S.; All authors have read and agreed to the published version of the manuscript.

Funding: This research received no external funding.

Data Availability Statement: No new data were created or analyzed in this study. Data sharing is not applicable to this article.

Conflicts of Interest: The authors declare no conflict of interest.

\section{References}

1. Wang, M.; Vandermaar, A.J.; Srivastava, K.D. Review of condition assessment of power transformer in service. IEEE Electr. Insul. Mag. 2002, 18, 12-25. [CrossRef]

2. Ortiz, F.; Fernandez, I.; Ortiz, A.; Renedo, C.J.; Delgado, F.; Fernandez, C. Health Indexes for power transformers: A case study. IEEE Electr. Insul. Mag. 2016, 32, 7-17. [CrossRef]

3. Bohatyrewicz, P.; Płowucha, J.; Subocz, J. Condition Assessment of Power Transformers Based on Health Index Value. Appl. Sci. 2019, 9, 4877. [CrossRef]

4. Zhang, X.; Gockenbach, E. Asset-management of transformers based on condition monitoring and standard diagnosis [feature article]. IEEE Electr. Insul. Mag. 2008, 24, 26-40. [CrossRef]

5. Mahmoudi, N.; Samimi, M.H.; Mohseni, H. Experiences with transformer diagnosis by DGA: Case studies. IET Gener. Transm. Distrib. 2019, 13, 5431-5439. [CrossRef]

6. Singh, S.; Bandyopadhyay, M.N. Dissolved gas analysis technique for incipient fault diagnosis in power transformers: A bibliographic survey. IEEE Electr. Insul. Mag. 2010, 26, 41-46. [CrossRef]

7. Przybylek, P.; Gielniak, J. Analysis of Gas Generated in Mineral Oil, Synthetic Ester, and Natural Ester as a Consequence of Thermal Faults. IEEE Access 2019, 7, 65040-65051. [CrossRef]

8. Betie, A.; Rao, U.M.; Fofana, I.; Fethi, M.; Yeo, Z. Influence of cellulose paper on gassing tendency of transformer oil under electrical discharge. IEEE Trans. Dielectr. Electr. Insul. 2019, 26, 1729-1737. [CrossRef]

9. IEEE. IEEE C57.104-2008_IEEE Guide for the Interpretation of Gases Generated in Oil-Immersed Transformers; (Revision of IEEE Std C57104-1991); IEEE: Toulouse, France, 2009.

10. Khan, S.A.; Equbal, M.D.; Islam, T. A comprehensive comparative study of DGA based transformer fault diagnosis using fuzzy logic and ANFIS models. IEEE Trans. Dielectr. Electr. Insul. 2015, 22, 590-596. [CrossRef]

11. Faiz, J.; Soleimani, M. Dissolved gas analysis evaluation in electric power transformers using conventional methods a review. IEEE Trans. Dielectr. Electr. Insul. 2017, 24, 1239-1248. [CrossRef]

12. Cigre. IEC/CEI 60599_Guide for the Interpretation of Dissolved and Free Gases Analysis; International Electrotechnical Commission: Geneva, Switzerland, 2007.

13. Duval, M. A review of faults detectable by gas-in-oil analysis in transformers. IEEE Electr. Insul. Mag. 2002, 18, 8-17. [CrossRef]

14. Duval, M. New techniques for dissolved gas in oil analysis. IEEE Electr. Insul. Mag. 2003, 19, 6-15. [CrossRef]

15. Duval, M.; Dukarm, J. Improving the reliability of transformer gas-in-oil diagnosis. IEEE Electr. Insul. Mag. 2005, 21, 21-27. [CrossRef]

16. Duval, M. The Duval Triangle for load tap changers, non-mineral oils and low temperature faults in transformers. IEEE Electr. Insul. Mag. 2008, 24, 22-29. [CrossRef]

17. Suwanasri, T.; Haema, J.; Phadungthin, R.; Suwanasri, C. Diagonostic Techniques to Evaluate Internal Condition of Power Transformer. In Proceedings of the 6th International Conference on Electrical Engineering/Electronics, Computer, Telecommunications and Information Technology, Pattaya, Thailand, 6-9 May 2009.

18. Akbari, A.; Setayeshmehr, A.; Borsi, H.; Gockenbach, E. A Software Implementation of the Duval Triangle Method. In Proceedings of the The 2008 IEEE International Symposium on Electrical Insulation, Vancouver, BC, Canada, 9-12 June 2008. 
19. Suwanasri, T.; Sirimongkol, P.; Suwanasri, C.; Phadungthin, R. Software Development for Power Transformer Condition Evaluation using Dissolved Gas Analysis Methods; Practical Experience in Thailand. In Proceedings of the 18th International Conference on Electrical Machines and Systems, Pattaya, Thailand, 25-28 October 2015.

20. Wannapring, E.; Suwanasri, C.; Suwanasri, T. Dissolved Gas Analysis Methods for Distribution Transformers. In Proceedings of the 13th International Conference on Electrical Engineering/Electronics, Computer, Telecommunications and Information Technology, Chiang Mai, Thailand, 28 June-1 July 2016.

21. Arshad, M.; Islam, S.M. Significance of cellulose power transformer condition assessment. IEEE Trans. Dielectr. Electr. Insul. 2011, 18, 1591-1598. [CrossRef]

22. Souahlia, S.; Bacha, K.; Chaari, A. Artificial intelligence tools aided-decision for power transformer fault diagnosis. Int. J. Comput. Appl. 2012, 38, 1. [CrossRef]

23. Su, Q.; Mi, C.; Lai, L.L.; Austin, P. Fuzzy dissolved gas analysis method for the diagnosis of multiple incipient faults in a transformer. IEEE Trans. Power Syst. 2000, 15, 593-598. [CrossRef]

24. Espinosa, J.; Vandewalle, J.; Wertz, V. Fuzzy Logic, Identification and Predictive Control, 1st ed.; Springer: Secaucus, NJ, USA, 2004.

25. Ross, T.J. Fuzzy Logic with Engineering Applications; John Wiley Sons: Hoboken, NJ, USA, 2009.

26. Abu-Siada, A.; Islam, S. A new approach to identify power transformer criticality and asset management decision based on dissolved gas-in-oil analysis. IEEE Trans. Dielectr. Electr. Insul. 2012, 19, 1007-1012. [CrossRef]

27. Huang, Y.-C.; Sun, H.-C. Dissolved gas analysis of mineral oil for power transformer fault diagnosis using fuzzy logic. IEEE Trans. Dielectr. Electr. Insul. 2013, 20, 974-981. [CrossRef]

28. Husain, Z. Fuzzy logic expert system for incipient fault diagnosis of power transformers. Int. J. Electr. Eng. Inform. 2018, 10, 300-317. [CrossRef]

29. Arshad, M.; Islam, S.M.; Khaliq, A. Fuzzy logic approach in power transformers management and decision making. IEEE Trans. Dielectr. Electr. Insul. 2014, 21, 2343-2354. [CrossRef]

30. Abu-Siada, A.; Hmood, S. A new fuzzy logic approach to identify power transformer criticality using dissolved gas-in-oil analysis. Int. J. Electr. Power Energy Syst. 2015, 67, 401-408. [CrossRef]

31. Ghoneim, S.; Taha, I. A new approach of DGA interpretation technique for transformer fault diagnosis. Int. J. Electr. Power Energy Syst. 2016, 81, 265-274. [CrossRef]

32. Ghoneim, S.S.M. Intelligent prediction of transformer faults and severities based on dissolved gas analysis integrated with thermodynamics theory. IET Sci. Meas. Technol. 2018, 12, 388-394. [CrossRef]

33. Duval, M.; dePabla, A. Interpretation of gas-in-oil analysis using new IEC publication 60599 and IEC TC 10 databases. IEEE Electr. Insul. Mag. 2001, 17, 31-41. [CrossRef]

34. Ajay, S.S.; Micah, B.M. Sampling techniques \& determination of sample size in applied statistics research: An overview. Int. J. Econ. Commer. Manag. 2014, 2, 2-22. 